\title{
Biliary complications in liver transplantation
}

\author{
See Ching Chan $\cdot$ Sheung Tat Fan
}

Received: 22 May 2008/Accepted: 16 July 2008/Published online: 3 September 2008

(C) Asian Pacific Association for the Study of the Liver 2008

\begin{abstract}
Biliary complications of living donor liver transplantation remain common. The complications of biliary leakage and stricture result in substantial recipient morbidity. A major focus of liver transplantation research is the prevention and reduction of these complications through identification of the multiple factors that are conducive to them. Such factors include the donor bile duct anatomy and quality, and the techniques of donor hepatectomy, recipient hepatectomy, and ductal reconstruction. A low threshold for re-exploration for possible bile leakage prevents development of uncontrolled sepsis. Return of good graft function can usually be expected after successful early endoscopic treatment. Contingent measures of percutaneous transhepatic dilatation and stenting, and revision hepaticojejunostomy have to be exercised with utmost care to avoid hepatic artery injury which may results in graft loss.
\end{abstract}

Keywords Biliary anastomosis - Complication . Living donor liver transplantation

\section{Introduction}

A successful liver transplantation entails a thousand operative steps performed precisely in the correct sequence. Last and not the least is biliary reconstruction. Biliary complications, namely leakage and stricture, result in

S. C. Chan · S. T. Fan $(\bowtie)$

Department of Surgery, Queen Mary Hospital, The University of Hong Kong, 102 Pokfulam Road, Pokfulam, Hong Kong, China e-mail: stfan@hku.hk

S. C. Chan

e-mail: seechingchan@gmail.com substantial morbidity and potential mortality of the recipient. In deceased donor liver transplantation (DDLT), biliary anastomosis is technically easier and could usually be accomplished in a duct-to-duct manner of the graft and recipient common ducts. Even so, a 15-25\% biliary stricture rate has been reported $[1,2]$. Strictures of duct-to-duct anastomosis are often amenable to endoscopic therapy [24]. A distinct entity that results from prolonged warm ischemia in non-heart beating donors causes diffuse ischemic biliary injury and manifests as multiple intrahepatic ductal strictures and abscesses [5]. This condition is not only prevalent (40\%) in recipients of non-heart beating donors, half of them are not amenable to endoscopic treatments $[6,7]$.

Living donor liver transplantation (LDLT) has a higher incidence of biliary complications than DDLT. The reported complication rate is up to $30 \%$ [8-11] and does not seem to improve significantly with experience [12]. Thus, it remains a major focus of research aiming to minimize long-term morbidity. In this synopsis on biliary complications of LDLT, we focus on the technical issues of biliary anastomosis, underlying surgical anatomy and biology. Technical faults that lead to biliary complications are discussed.

\section{Standard techniques}

Donor hepatectomy

The goal of donor hepatectomy is to obtain a large enough liver graft of good quality for successful implantation in the recipient and to leave behind a remnant liver of adequate size for uneventful recovery of the donor. The recipient will require a liver graft of more than $35 \%$ [13] of the estimated 
standard liver volume [14], whereas the donor needs to have a remnant liver of at least $30 \%$ of the total liver volume [15]. Unless the donor has a body size substantially larger than the recipient, the left liver, which is usually only $33 \%$ of the total liver volume, is inadequate in size for the recipient. Therefore, the right liver graft is often required and has become the workhorse of adult LDLT.

Although donor right hepatectomy including the middle hepatic vein has been described elsewhere [16], in the context of biliary complications, the approach to the right hepatic duct (RHD) deserves a more detailed description. An operative cholangiogram (OC) is obtained by instillation of undiluted contrast agent via an Fr3.5 Argyle catheter in the common bile duct inserted through the cystic duct. To avoid damaging aberrant sectoral branches of the RHD, the cystic duct is not cannulated before the entire gallbladder is detached from the gallbladder fossa. The peritoneum on the right side of the common hepatic duct is released by sharp dissection. The lower border of the RHD often then comes into view. The planned division line of the RHD 3-4 mm away from the ductal bifurcation is marked with a large Liga clip (Ethicon Ltd, Edinburgh, UK). The first OC is then performed (Fig. 1a). A marking is made with diathermy on the liver surface with reference to the Liga clip as appeared on the OC. The portion of right hepatic artery on entering the liver should not be denuded to preserve small twigs supplying the RHD. Liver transection is then executed using the Cavitron ultrasonic surgical aspirator (CUSA) (Valley Lab, Boulder, CO) along the Cantlie line and onto the left of the middle hepatic vein. At the liver hilum, it is headed toward the marking on the liver of the RHD planned division line.

The arterial [17] and venous [18] vascular plexus around the right and left hepatic ducts and common hepatic duct should not be disrupted by overzealous application of the CUSA. After minimal exposure of the right pedicle, a large Liga clip is applied again at the planned line of division and OC is performed for the second time. In the situation when the right posterior hepatic duct arises from the left hepatic duct, the posterior duct is also marked by another large Liga clip (Fig. 1b). The true anteroposterior view of the liver and bile ducts is made with the $\mathrm{C}$-arm rotated to the right (counterclockwise). Thus, the best view is made with the ductal bifurcation close to but not yet overlapping the vertebral column. This is the true anteroposterior view of the biliary system. With such maneuver, the right posterior hepatic duct will move "with" the direction of the duct and become more lateral, hence the parallax technique.

After confirming that the planned line of division is optimal, the RHD within the pedicle is then severed with scissors. This is made in a plane tangential to the liver transection surface, which is much horizontal. Bleedings from arterial branches on both severed ends of the RHD are plicated with 6-0 Prolene. The right hepatic duct stump is plicated with 6-0 PDS (polydioxanone) in a continuous manner. The third OC is performed to ascertain the patency and integrity of the main and left ductal systems (Fig. 1c). Dilute methylene blue is also instilled gently through the Argyle catheter to identify any site of bile leakage.

Alternative techniques for isolation and division of the RHD have been described by other centers. Encircling of the right pedicle prior to division may injure the right posterior hepatic duct and caudate branches [19]. Probing of the RHD is also practiced [20]. This additional invasive maneuver may result in late complication of the donor from main bile duct ischemia [21, 22]. After all, these techniques cannot replace demonstration of the biliary anatomy by OC.
Fig. 1 (a) Operative

cholangiogram revealed right anterior and posterior hepatic ducts of separate junctions with the common hepatic duct. A metal clip was applied on the liver capsule at the appropriate position of the planned line of division of the right anterior hepatic duct. (b) The second operative cholangiogram was performed with the second metal clip applied close to the right posterior hepatic duct. (c) The third operative cholangiogram was performed to confirm the patency and integrity of the left and common hepatic ducts
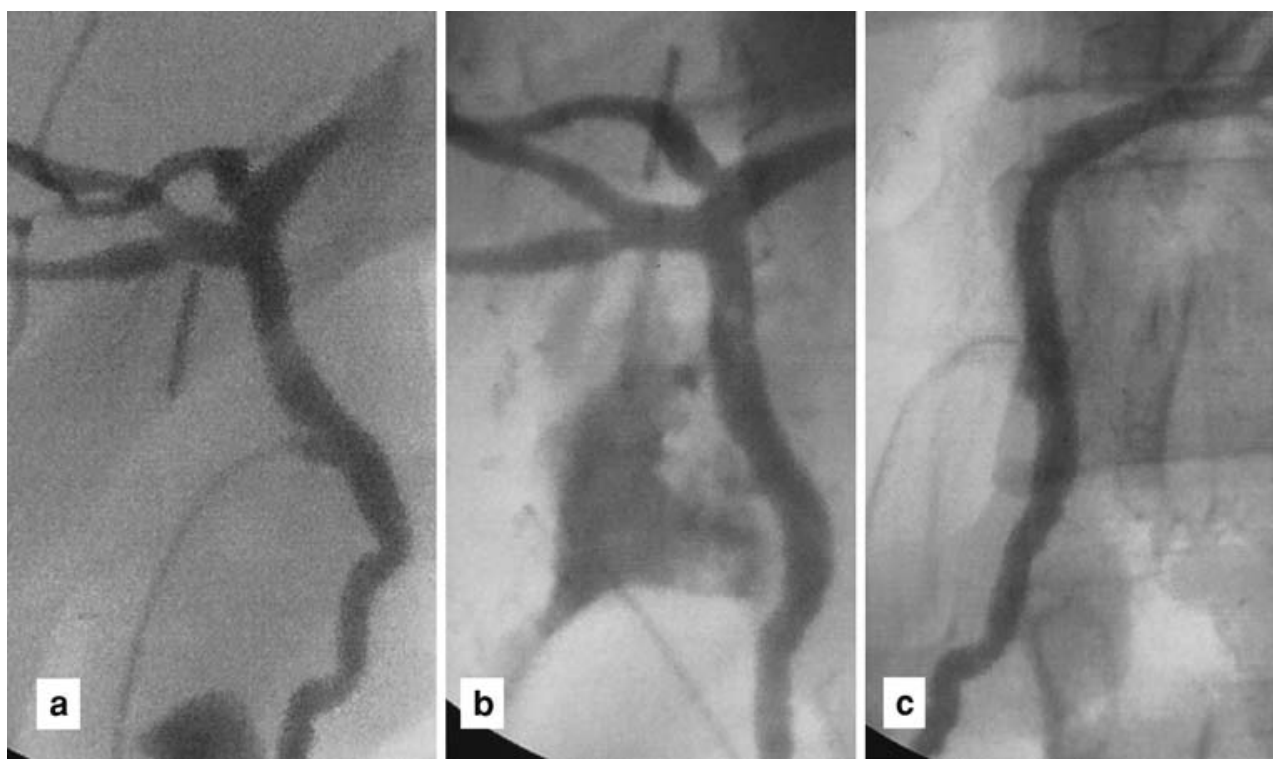
The right liver graft once delivered from the donor is immediately flushed with histidine-tryptophan-ketoglutarate solution (HTK) on the back table via the right portal vein, right hepatic artery, and the RHD [23]. Utmost care is taken in flushing the right hepatic artery because intimal tear of the right hepatic artery results in unsalvageable damage to the liver graft. HTK, which has lower viscosity than University of Wisconsin solution, has the potential advantage of more thorough flushing of the arterial supply of the biliary system. It has been shown that the biliary stricture rate was lower in DDLT recipients in whom the grafts were flushed with HTK instead of University of Wisconsin solution $(17 \%$ vs. $30 \%, P<0.05)$ [24].

\section{Recipient hepatectomy}

For LDLT, total hepatectomy of the native liver requires preservation of the inferior vena cava. There is always a tendency to preserve a long length of the common hepatic duct for worry of inadequate length for duct-to-duct anastomosis with the right liver graft devoid of the common hepatic duct. However, ischemia of the recipient common hepatic duct is a main factor for development of ischemic biliary strictures. Since blood supply of the common hepatic duct is from an arcade supplied from the right hepatic artery, right and left gastric arteries, and gastroduodenal artery [25, 26], such branches ought to be preserved during recipient hepatectomy. A group has even introduced the intrahepatic Glissonian approach for recipient hepatectomy to maintain vascular supply and drainage and length of the native bile ducts [27]. However, should the right hepatic artery be located in a very cephalic position, it becomes unpractical for preservation of such tributaries. Blood supply is therefore from the branches of the gastroduodenal and right gastric arteries. While too long a common hepatic duct could only result in relative ischemia jeopardizing anastomosis with subsequent ischemic stricture, a short common hepatic duct of the recipient should not prohibit duct-to-duct anastomosis.

The presence of gallstones in the recipient and a dilated common bile duct should raise the suspicion of common ductal stones. Choledochoscopy should be performed prior to ductal anastomosis.

\section{Duct-to-duct anastomosis}

Duct-to-duct anastomosis is an attractive method for biliary reconstruction because fashioning of a Roux-en-Y loop for hepaticojejunostomy, an additional operative procedure, is avoided, and endoscopic treatment of ductal anastomotic stricture in the future is made feasible. In the event of bile leakage through the anastomosis, severe sepsis from contamination of peritoneal cavity by bowel contents [10] is also avoided.
A single RHD is most favorable for duct-to-duct anastomosis. Usually, the recipient common hepatic duct orifice is larger than the graft RHD. Should the ratio be more than two, reduction of the former by plication to a size slightly larger than the RHD orifice is necessary. Matching is of the ductal lumen instead of the outer circumference because the recipient bile duct is usually thicker and has developed varices from portal hypertension. In the case when the right anterior and posterior ducts are separated but not more than $3 \mathrm{~mm}$ apart, duct-to-duct anastomosis is still possible. The hilar plate tissue is incorporated into the anastomosis, otherwise biliary leakage will occur. Conversion of two openings into one by ductoplasty is not always advisable because suturing results in ductal ischemia and fibrosis, resulting in stricture formation [28]. When the distance between the two openings is more than $3 \mathrm{~mm}$, two separate hepaticojejunostomies using the Roux-en-Y loop are advisable.

Continuous suture in principle is more prone to strangulation and ischemia of the ductal structure. However, on the posterior wall, insertion of interrupted sutures with knots outside the lumen is difficult. Using 6-0 PDS, the posterior wall is reconstructed with continuous sutures (Fig. 2a). Overzealous knot tying will either strangulate the ductal tissue or break the suture. The anterior wall including the corners is reconstructed with interrupted sutures (Fig. 2b). An important factor leading to stricture is subclinical leakage of bile resulting in infection and scarring of the anastomosis. Thus, gentle handling of the ductal tissue and smooth passage of needle and suture is mandatory.

Stenting is not practiced as the stent itself is a foreign body and will induce inflammation and subsequent stricture formation. Biliary stent and T-tube are independent factors for biliary complications [29]. Only in the case when the ductal orifice is small (e.g. $2 \mathrm{~mm}$ ) stenting may be the best compromise to reduce the chance of leakage and maintain the duct anastomosis patency. An Fr3.5 Argyle tube is used and exits through the native cystic duct if possible [24, 30]. It provides a subhepatic course and is connected to a bag in the early postoperative period. Subsequent cholangiogram is performed to ensure no leakage and free flow of contrast into the duodenum. The catheter is not removed until 10 weeks after the operation.

\section{Hepaticojejunostomy}

A lower biliary anastomotic stricture was suggested in a study, but this is offset by many other advantages of ductto-duct anastomosis mentioned earlier [31]. Another study in fact showed no difference in the stricture rate between the two [28]. Indeed, there is to date no randomized study comparing the two methods. For the single duct, duct-toduct anastomosis is preferred except in special situations, for example, primary sclerosing cholangitis [32] and 
Fig. 2 (a) Duct-to-duct biliary anastomosis with the posterior wall was performed by continuous suturing. (b) Ductto-duct biliary anastomosis with anterior wall and corners was performed by interrupted suturing
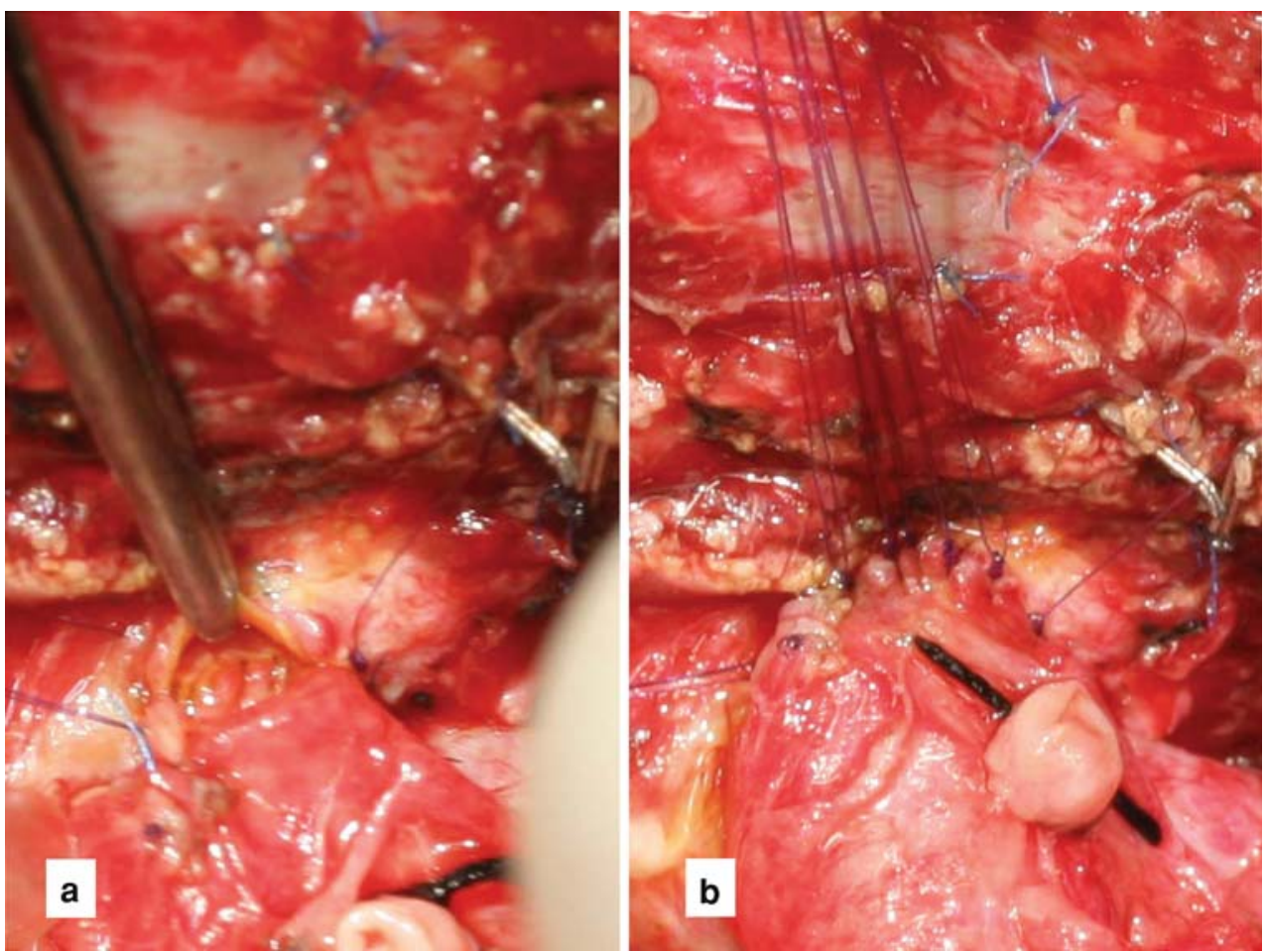

Caroli's disease [33]. When there are more than two hepatic ducts in the graft or the distance between them is more than $3 \mathrm{~mm}$, hepaticojejunostomy becomes necessary. The Roux-en-Y loop should have a length of $40 \mathrm{~cm}$ to minimize bile reflux into the stomach causing gastritis. The enterotomies are made by diathermy using the cutting mode to reduce necrosis. The size of the enterotomies should be of the same size because the ductal opening as there is always a tendency for the jejunum to contract as a reaction to the diathermy. The Roux-en-Y loop is brought to the graft via a retrocolic and retrograstric route, which is most direct. Entero-biliary anastomosis is started with the bile duct of more difficult access. The posterior wall is done with continuous suture and anterior wall interrupted 6-0 PDS. Mesocolic and mesenteric windows are closed carefully with non-absorbable sutures to prevent internal herniation of the bowel [34].

\section{Management of biliary stricture}

Endoscopic retrograde cholangiopancreatography (ERCP) and dilatation with catheters are useful for recipients with
Fig. 3 (a) Short biliary anastomotic stricture involving right anterior and posterior hepatic ducts as demonstrated by endoscopic retrograde cholangiogram. (b) Biliary stricture expanded by dilatation catheter inserted via a duodenoscope. (c) Biliary anastomotic stricture eliminated after two sessions of endoscopic dilatation and stenting
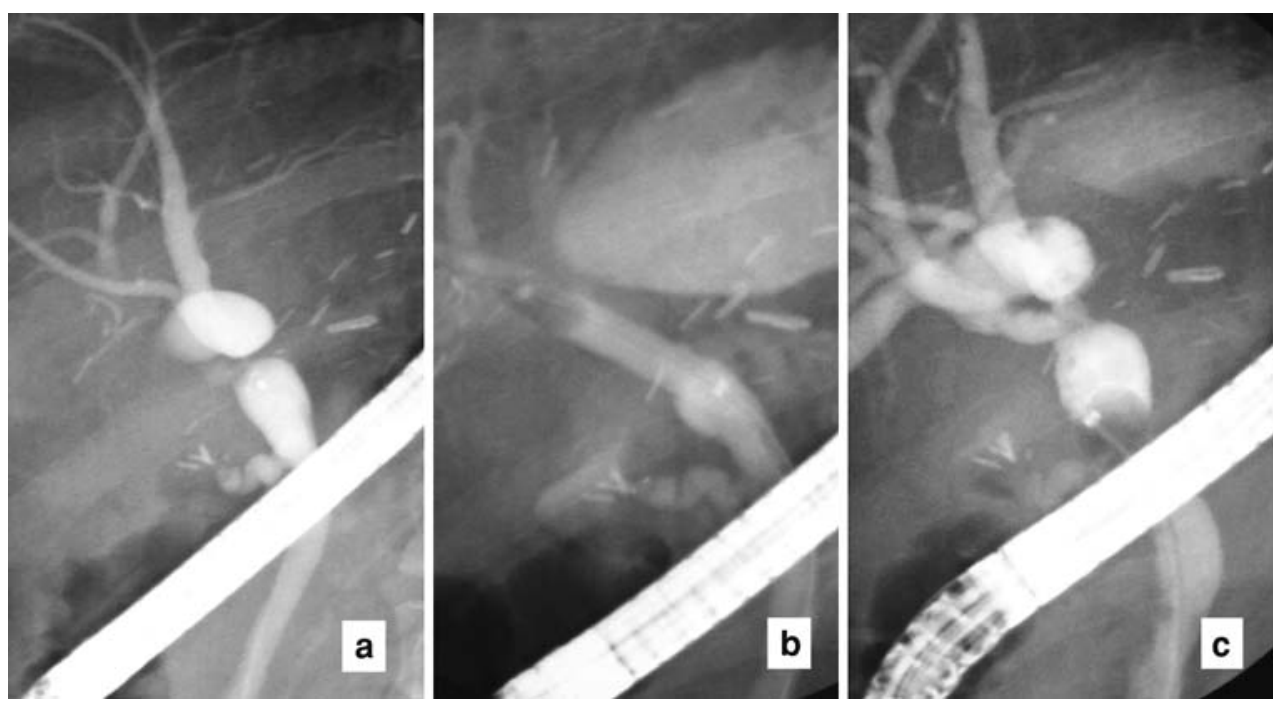
duct-to-duct reconstruction. The success rate of ERCP in treating biliary stricture is high $(75 \%)$ [35]. Short biliary anastomotic strictures (Fig. 3a) are usually amenable to dilatation by ERCP (Fig. 3b), followed by temporary stenting. After two or more sessions of ERCP and dilatation, the stricture could be eliminated (Fig. 3c). However, it is more difficult if the stricture is long and extends into the graft and segregates the right anterior and posterior hepatic ducts. Percutaneous transhepatic biliary drainage (PTBD) becomes the alternative measure and is usually successful $[36,37]$. In the situation when the intrahepatic ducts are not dilated and cannulation under ultrasound guidance is difficult, the risk of injury to the hepatic artery and portal veins is increased. Hemobilia, pseudoaneurysm of the hepatic artery, arterioportal fistula, and portal vein thrombosis are known complications of PTBD [38].

Therefore, the policy of a low-threshold for exploration and revision hepaticojejunostomy is adopted. Revision hepaticojejunostomy is a major undertaking, but it is necessary when biliary stricture is too long to improve by repeated dilatation. In the procedure, meticulous care is needed to avoid damage to the hepatic artery near the biliary anastomosis. Prior PTBD that remains in situ can guide localization of the bile duct either by fluoroscopy or instillation of methylene blue. The bile duct may not have a well-formed ductal mucosa but may be lined by connective tissues. Nevertheless, the already dilated bile duct proximal to the stricture allows a new anastomosis with the Roux-en$\mathrm{Y}$ loop of good patency. A stent is placed across the anastomosis and exits via a Witzel tunnel. Cholangiogram is done through the biliary tract 6 weeks after the operation and before removal of the stent.

\section{Conclusion}

Biliary complications remain common in both DDLT and LDLT. Solutions to technical issues start with methodical donor hepatectomy by precise and clean division of the RHD while not damaging the donor main duct. Recipient hepatectomy should not compromise the blood supply of the common hepatic duct. Multiple ducts of the donor not only increase the technical difficulty of biliary reconstruction, but it is also a factor for development of biliary complications. Preoperative demonstration of the donor biliary anatomy by imaging is feasible $[39,40]$. This may assist the surgeon in appraising the anatomy. Rarely, multiple right hepatic ducts prohibit the use of the right liver as a graft [41]. Whether this should be brought up as a factor for donor evaluation is considered controversial. Perhaps, it is only relevant when all other factors, particularly the degree of enthusiasm of the donor to donate, are equal among multiple potential donors of a recipient.

\section{References}

1. Busuttil RW, Farmer DG, Yersiz H, Hiatt JR, McDiarmid SV, Goldstein LI, et al. Analysis of long-term outcomes of 3200 liver transplantations over two decades: a single-center experience. Ann Surg 2005;241:905-916. doi:10.1097/01.sla.0000164077.77 912.98

2. Rerknimitr R, Sherman S, Fogel EL, Kalayci C, Lumeng L, Chalasani N, et al. Biliary tract complications after orthotopic liver transplantation with choledochocholedochostomy anastomosis: endoscopic findings and results of therapy. Gastrointest Endosc 2002;55:224-231. doi:10.1067/mge.2002.120813

3. Perkins JD. Evolving treatment of biliary strictures following liver transplantation. Liver Transpl 2007;13:1605-1607

4. Pasha SF, Harrison ME, Das A, Nguyen CC, Vargas HE, Balan $\mathrm{V}$, et al. Endoscopic treatment of anastomotic biliary strictures after deceased donor liver transplantation: outcomes after maximal stent therapy. Gastrointest Endosc 2007;66:44-51. doi: 10.1016/j.gie.2007.02.017

5. Chan SC, Lo CM, Liu CL, Fan ST. Resurgence of biliary cast syndrome. Liver Transpl 2005;11:242-243. doi:10.1002/lt.20331

6. Suarez F, Otero A, Solla M, Arnal F, Lorenzo MJ, Marini M, et al. Biliary complications after liver transplantation from Maastricht category-2 non-heart-beating donors. Transplantation 2008;85:9-14

7. Lee HW, Suh KS, Shin WY, Cho EH, Yi NJ, Lee JM, et al. Classification and prognosis of intrahepatic biliary stricture after liver transplantation. Liver Transpl 2007;13:1736-1742. doi:10.1002/lt.21201

8. Soejima Y, Taketomi A, Yoshizumi T, Uchiyama H, Harada N, Ijichi $\mathrm{H}$, et al. Biliary strictures in living donor liver transplantation: incidence, management, and technical evolution. Liver Transpl 2006;12:979-986. doi:10.1002/lt.20740

9. Tsujino T, Isayama H, Sugawara Y, Sasaki T, Kogure H, Nakai $\mathrm{Y}$, et al. Endoscopic management of biliary complications after adult living donor liver transplantation. Am J Gastroenterol 2006;101:2230-2236. doi:10.1111/j.1572-0241.2006.00797.x

10. Gondolesi GE, Varotti G, Florman SS, Munoz L, Fishbein TM, Emre SH, et al. Biliary complications in 96 consecutive right lobe living donor transplant recipients. Transplantation 2004;77:18421848. doi:10.1097/01.TP.0000123077.78702.0C

11. Liu CL, Lo CM, Chan SC, Fan ST. Safety of duct-to-duct biliary reconstruction in right-lobe live-donor liver transplantation without biliary drainage. Transplantation 2004;77:726-732. doi:10.1097/01.TP.0000116604.89083.2F

12. Morioka D, Egawa H, Kasahara M, Ito T, Haga H, Takada Y, et al. Outcomes of adult-to-adult living donor liver transplantation: a single institution's experience with 335 consecutive cases. Ann Surg 2007;245:315-325. doi:10.1097/01.sla.0000236600. 24667.a4

13. Fan ST, Lo CM, Liu CL, Yong BH, Wong J. Determinants of hospital mortality of adult recipients of right lobe live donor liver transplantation. Ann Surg 2003;238:864-869

14. Urata K, Kawasaki S, Matsunami H, Hashikura Y, Ikegami T, Ishizone S, et al. Calculation of child and adult standard liver volume for liver transplantation. Hepatology 1995;21:1317-1321

15. Fan ST, Lo CM, Liu CL, Yong BH, Chan JK, Ng IO. Safety of donors in live donor liver transplantation using right lobe grafts. Arch Surg 2000;135:336-340. doi:10.1001/archsurg.135.3.336

16. Fan ST, Lo CM, Liu CL. Technical refinement in adult-to-adult living donor liver transplantation using right lobe graft. Ann Surg 2000;231:126-131. doi:10.1097/00000658-200001000-00018

17. Stapleton GN, Hickman R, Terblanche J. Blood supply of the right and left hepatic ducts. Br J Surg 1998;85:202-207. doi:10.1046/ j.1365-2168.1998.00511.x 
18. Couinaud C. The parabiliary venous system. Surg Radiol Anat 1988;10:311-316. doi:10.1007/BF02107904

19. Takatsuki M, Eguchi S, Tokai H, Hidaka M, Soyama A, Tajima $\mathrm{Y}$, et al. A secured technique for bile duct division during living donor right hepatectomy. Liver Transpl 2006;12:1435-1436. doi:10.1002/lt.20877

20. Testa G, Malago M, Porubsky M, Marinov M, Sankary H, Oberholzer $\mathrm{J}$, et al. Hilar early division of the hepatic duct in living donor right hepatectomy: the probe-and-clamp technique. Liver Transpl 2006;12:1337-1341. doi:10.1002/lt.20821

21. Tamura S, Sugawara Y, Makuuchi M. Choledochotomy in live liver donors. Liver Transpl 2007;13:173. doi:10.1002/lt.20996

22. Morelli G, Reed A, Firpi RJ, Machicao V, Abdelmalek MF, Soldevilla-Pico C, et al. Late presentation of a biliary tract complication after right hepatic donation resulting in secondary biliary cirrhosis. Liver Transpl 2006;12:306-309. doi:10.1002/lt.20687

23. Chan SC, Liu CL, Lo CM, Fan ST. Applicability of histidinetryptophan-ketoglutarate solution in right lobe adult-to-adult live donor liver transplantation. Liver Transpl 2004;10:1415-1421. doi:10.1002/lt.20243

24. Welling TH, Heidt DG, Englesbe MJ, Magee JC, Sung RS, Campbell DA, et al. Biliary complications following liver transplantation in the model for end-stage liver disease era: effect of donor, recipient, and technical factors. Liver Transpl 2008;14:73-80. doi:10.1002/lt.21354

25. Parke WW, Michels NA, Ghosh GM. Blood supply of the common bile duct. Surg Gynecol Obstet 1963;117:47-55

26. Vellar ID. The blood supply of the biliary ductal system and its relevance to vasculobiliary injuries following cholecystectomy. Aust N Z J Surg 1999;69:816-820. doi:10.1046/j.1440-1622. 1999.01702.x

27. Lee KW, Joh JW, Kim SJ, Choi SH, Heo JS, Lee HH, et al. High hilar dissection: new technique to reduce biliary complication in living donor liver transplantation. Liver Transpl 2004;10:11581162. doi: $10.1002 / \mathrm{lt} .20230$

28. Shah SA, Grant DR, McGilvray ID, Greig PD, Selzner M, Lilly LB, et al. Biliary strictures in 130 consecutive right lobe living donor liver transplant recipients: results of a Western center. Am J Transplant 2007;7:161-167. doi:10.1111/j.1600-6143.2006.01 601.X

29. Qian YB, Liu CL, Lo CM, Fan ST. Risk factors for biliary complications after liver transplantation. Arch Surg 2004;139: 1101-1105. doi:10.1001/archsurg.139.10.1101

30. Ishiko T, Egawa H, Kasahara M, Nakamura T, Oike F, Kaihara S, et al. Duct-to-duct biliary reconstruction in living donor liver transplantation utilizing right lobe graft. Ann Surg 2002;236: 235-240. doi:10.1097/00000658-200208000-00012
31. Kasahara M, Egawa H, Takada Y, Oike F, Sakamoto S, Kiuchi T, et al. Biliary reconstruction in right lobe living-donor liver transplantation: comparison of different techniques in 321 recipients. Ann Surg 2006;243:559-566. doi:10.1097/01.sla.0000 206419.65678.2e

32. Cholongitas E, Shusang V, Papatheodoridis GV, Marelli L, Manousou P, Rolando N, et al. Risk factors for recurrence of primary sclerosing cholangitis after liver transplantation. Liver Transpl 2008;14:138-143. doi:10.1002/lt.21260

33. Millwala F, Segev DL, Thuluvath PJ. Caroli's disease and outcomes after liver transplantation. Liver Transpl 2008;14:11-17. doi:10.1002/lt.21366

34. Liu CL, Lo CM, Chan SC, Fan ST, Wong J. Internal hernia of the small bowel after right-lobe live donor liver transplantation. Clin Transplant 2004;18:211-213. doi:10.1046/j.1399-0012.2003.00 125. $\mathrm{x}$

35. Shah JN, Ahmad NA, Shetty K, Kochman ML, Long WB, Brensinger CM, et al. Endoscopic management of biliary complications after adult living donor liver transplantation. Am J Gastroenterol 2004;99:1291-1295. doi:10.1111/j.1572-0241.2004.30775.x

36. Egawa H, Inomata Y, Uemoto S, Asonuma K, Kiuchi T, Fujita S, et al. Biliary anastomotic complications in 400 living related liver transplantations. World J Surg 2001;25:1300-1307. doi:10.1007/ s00268-001-0114-4

37. Cheng YF, Chen CL, Chen YS, Huang TL, Chen TY, Lee TY, et al. Interventional radiology in the treatment of post-liver transplant complications. Transplant Proc 2000;32:2196-2197. doi:10.1016/S0041-1345(00)01632-8

38. Fan ST, Lo CM, Liu CL, Tso WK, Wong J. Biliary reconstruction and complications of right lobe live donor liver transplantation. Ann Surg 2002;236:676-683. doi:10.1097/00000658-20021100000019

39. Yeh BM, Breiman RS, Taouli B, Qayyum A, Roberts JP, Coakley FV. Biliary tract depiction in living potential liver donors: comparison of conventional MR, mangafodipir trisodiumenhanced excretory MR, and multi-detector row CT cholangiography-initial experience. Radiology 2004;230:645-651. doi: 10.1148/radiol.2303021775

40. Schroeder T, Malago M, Debatin JF, Goyen M, Nadalin S, Ruehm SG. "All-in-one" imaging protocols for the evaluation of potential living liver donors: comparison of magnetic resonance imaging and multidetector computed tomography. Liver Transpl 2005;11:776-787. doi:10.1002/lt.20429

41. Liu CL, Lo CM, Chan SC, Tso WK, Fan ST. The right may not be always right: biliary anatomy contraindicates right lobe live donor liver transplantation. Liver Transpl 2004;10:811-812. doi:10.1002/lt.20193 